Tendo como eixo o direito à educação para todos, explora-se particularmente neste texto como tal direito vem se concretizando para parcela de alunos deficientes fisicos, sensoriais ou mentais que, para seu desenvolvimento, muitas vezes demandam condições não usualmente disponíveis nos sistemas de ensino. Procura-se evidenciar o potencial de exclusão que decorre dos princípios que vêm norteando, na atualidade, as políticas educacionais, no contexto de reforma do Estado, evidenciando sua contradição com o discurso da inclusão escolar. Inclusão; política educacional; educação especial

\section{SCHOOL INCLUSION}

AND SPECIAL

EDUCATION:

CONSIDERATIONS ON

BRAZILIAN

EDUCATIONAL POLICY

The authors explore how the riaght to "Education for all" is becoming a reality for part of physical, sensorial, and mental handicapped students. These students demand unusual conditions which are not available in the learning systems. The authors try to show the potential of exclusion that comes fiom principles which direct the educational policies. These principles contradict the school inclusion discourse. Inclusion; educational policy; special education

\section{INCLUSÃO ESCOLAR E EDUCAÇÃO ESPECIAL: CONSIDERAÇÕES SOBRE A POLÍTICA EDUCACIONAL BRASILEIRA}

\author{
Marcos José da Silveira Mazzotta \\ Sandra M. Zákia L. Sousa
}

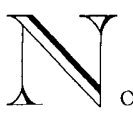

o Brasil, particularmente nos anos 90 , o tema da inclusão escolar tem estado presente nos estudos, debates e proposições de professores, pesquisadores, gestores, pais e alunos, direta ou indiretamente, envolvidos com a educação especial. Esse tema, em última instância, nos remete à análise de como vem se concretizando o direito à educação em nossa realidade.

Sem dúvida, discutir-se a concretização do direito de todos à educação escolar implica a conside-

Professor titular da Universidade Presbiteriana Mackenzie, professor associado da Universidade de São Paulo, membro-fundador do Laboratório Interunidades de Estudos sôbre Deficiências (Lide), do Instituto de Psicologia da USP. Professora doutora da Faculdade de Educação da Universidade de São Paulo. 
ração da multiplicidade de manifestações de exclusão, seja social, racial, de gênero ou das pessoas deficientes na sociedade e na escola. Ou seja, ao se assumir a perspectiva da inclusão, tem-se como suposto o reconhecimento da exclusão, "processo complexo e multifacetado, uma configuração de dimensões materiais, políticas, relacionais e subjetivas. É processo sutil e dialético, pois só existe em relação à inclusão como parte constitutiva dela. Não é uma coisa ou um estado, é processo que envolve o homem por inteiro e suas relações com os outros. Não tem uma única forma e não é falha do sistema, (...) é produto do funcionamento do sistema" (Sawaia, 1999, p.9).

O processo de exclusão, no entanto, concretiza-se de diversas maneiras e com diferentes intensidades, não só em relação ao tempo e espaço em que ocorre, mas também em relação aos segmentos e pessoas envolvidas. Assim, não devemos abstrair dos mecanismos específicos de discriminação ou marginalização dos deficientes, sob o risco de, em nome de uma educação para todos, manter, temporariamente, dados alunos na escola sem que lhes sejam garantidas condições de aprendizagem.

Neste texto, as considerações têm como foco a educação escolar de alunos com deficiência e que demandam, para seu desenvolvimento, condições não usualmente disponíveis nos sistemas de ensino, para concretização de seu direito à educação. Embora nosso horizonte seja a concretização de uma educação comum inclusiva, não se pode abstrair do potencial de exclusão que decorre dos princípios que vêm norteando, na atualidade, as políticas educacionais, no contexto de reforma do Estado. Procura-se indicar os impactos dessa reforma na gestão educacional, analisando-se particularmente a concepção de avaliação de sistemas de ensino que tem sido dominante em iniciativas governamentais.

\section{EDUCAÇÃO ESCOLAR: DIMENSÃO PÚBLICA}

De início convém lembrar que, mesmo numa rápida incursão em nossa política educacional, podemos constatar registros que revelam preocupações governamentais com a educação para todos. Embora constando de documentos oficiais, tais preocupações, intenções ou prerrogativas não têm sido acompanhadas de ações que as tornem realidade.

Reiterada sempre como propósito consensual e inquestionável numa sociedade democrática, a educação para todos, em diversos momentos de nossa história, mereceu e vem merecendo importan- 
tes debates, tanto por iniciativas governamentais como não-governamentais ${ }^{1}$.

Para não nos determos em tantas reminiscências, ainda que importantes, é oportuno lembrar aqui, por exemplo, o tão propalado “Dia D", ou Dia Nacional de Debate sobre Educação, ocorrido em 18 de setembro de 1985, promovido pelo Ministério da Educação e envolvendo educadores, comunidade, instituições e sociedade em geral. Tal debate se deu no contexto da política educacional da "Nova República", segundo a qual "a educação brasileira, sob a égide dos princípios da democratização, participação e descentralização, deverá garantir a todos um ensino de qualidade, fator essencial à consolidação da democracia" (Brasil, 1985, p.9). O tema norteador das discussões foi "a escola que temos e a escola que queremos” em vista de uma Educação para Todos - Caminho para a Mudança.

Outro debate importante, também de iniciativa do Ministério da Educação, foi desencadeado em maio de 1994 tendo como alvo - Plano Decenal de Educação para Todos - 1993/2003. Tal plano inspirou-se na Declaração Mundial sobre a Educação para Todos: Satisfação das Necessidades Básicas de Aprendizagem, aprovada na Conferência Mundial realizada em 1989, em Jomtien, na Tailândia. Tendo como núcleo "o imperativo de universalização com qualidade, aspiração maior da sociedade brasileira, com a conseqüente erradicação do analfabetismo", inclui a preocupação com a "integração à escola de crianças e jovens portadores de deficiência e, quando necessário, o apoio a iniciativas de atendimento especializado" (Brasil, 1993, p.48).

Diversos outros eventos registram-se a partir da edição da Política Nacional de Educação Especial, em 1993, baseada no referido Plano Decenal e no Estatuto da Criança e do Adolescente, de 1990; bem como após a Declaração de Salamanca e linhas de ação sobre necessidades educativas especiais, aprovada pela Conferência Mundial, de 1994, organizada pelo governo da Espanha com a cooperação da Unesco. Esses documentos nacionais e internacionais apontam para posicionamentos, rumos e recomendações dirigidos à ação das organizações governamentais e não-governamentais na área da educação.

É oportuno assinalar que a Declaração de Salamanca tem sido o referencial básico para os mais recentes debates sobre Educação para Todos com a denominação "Educação Inclusiva”, em razão de firmar posição consensual comprometida com o "ensino ministrado, no sistema comum de educação, a todas as crianças, jovens e adultos com necessidades educativas especiais". Propugna que "as escolas devem acolher a todas as crianças, independentemente de 
suas condições físicas, intelectuais, sociais, emocionais, lingüisticas ou outras", reiterando que "as escolas devem ser capazes de ter sucesso na educação de todos os alunos, inclusive os que sofrem deficiências graves" (Brasil, 1997, p.17).

Tais recomendações não são absolutamente novas. Haja vista o que foi aqui rememorado apontando apenas alguns atos e eventos em que essas posições político-ideológicas estão explicitadas. Entretanto é fundamental observar que os princípios e propostas contidos nessa Declaração de 1994 refletem a consolidação de anseios de grupos organizados, com renovado poder de pressão sobre os órgãos governamentais e fortalecimento da convicção da importância e urgência de transformações sócio-educacionais compatíveis com o imprescindivel respeito à diversidade do ser humano.

Parece óbvio e simples ressaltar a diversidade do ser humano. Todavia, no âmbito da sociedade globalizada, que prima pelo controle do comportamento de seus membros com vistas à padronização, as diferenças e desigualdades acabam sendo interpretadas como questões meramente individuais. É importante compreendermos que "a pluralidade é a condição da ação humana pelo fato de sermos todos os mesmos, isto é, humanos, sem que ninguém seja exatamente igual a qualquer pessoa que tenha existido, exista ou venha a existir" (Arendt, 1997, p.16). São os homens e as mulheres, e não o homem e a mulher, que vivem na Terra. É a paradoxal pluralidade de seres singulares. Seja do ponto de vista 
biológico ou social, é preciso que se atente para a variedade na unidade $e$ a unidade na variedade como condição da vida humana.

No espaço público, essa igualdade de desiguais precisa ser assegurada sob certos aspectos e por motivos específicos, já que ela não decorre da natureza humana. Daí a necessidade fundamental da participação social de todos na produção, gestão e fruição dos bens e serviços de uma sociedade democrática.

Nesse entendimento, todo aquele que se isola, ou é excluído da participação ativa no convívio social, torna-se impotente e perde a condição de sujeito de suas ações. Mesmo porque, é oportuno lembrar, cada vez mais "são os grupos organizados que têm poder para criar direito, e só o direito pode limitar o poder", lembrando aqui o ilustre pensador italiano Norberto Bobbio.

É mediante a participação ativa na família, no trabalho, no lazer, ou seja, nos variados grupos sociais e comunitários, além da escola, que se dá a educação para a cidadania. Nesse sentido, cabe esclarecer, com apoio em Habermas, que "a violência, exercida por meio da ação estratégica, é a capacidade de impedir outros indivíduos ou grupos de defenderem os seus próprios interesses” (Freitag \& Rouanet, 1993, p.112).

Numa sociedade em que a crescente falta de respeito a si e ao outro se exterioriza em discriminação negativa, competição, corrupção, marginalização e exclusão; em que a solidariedade, tolerância, aceitação e cooperação têm sido atitudes raras em suas variadas instâncias; e a ética tem sido algo cada vez mais distante e desconhecido nas relações humanas, por certo muito se espera da escola.

Sendo um espaço público de capital importância na construção da cidadania, para cumprir essa função, a escola tem de ser organizada de modo que atenda a diversidade dos educandos, configurando-se como uma instituição social aberta e destinada a todos, com sentido integrador ou inclusivo.

O fundamental é que a escola se firme como espaço privilegiado das relações sociais para todos, não ignorando, portanto, aqueles que apresentem necessidades educacionais especiais. Em outros termos, acolhendo "crianças com deficiências e crianças bem dotadas, crianças que vivem nas ruas e que trabalham, crianças de populações distantes ou nômades, crianças de minorias lingüísticas, étnicas ou culturais e crianças de outros grupos ou zonas desfavorecidos ou marginalizados (...)" (Brasil, 1997, p.18), conforme aponta a Declaração de Salamanca.

Tal escola, como instrumento social coerente com uma educação inclusiva, calcada em atitudes éticas que se concretizam no respeito mútuo mediado pela competência, deve atuar para além das restrições de sentido impostas aos termos integração e inclusão, muitas vezes, com propósitos meramente ideológicos.

É preciso que se deixe de impor slogans, como "o professor especializado em todos os alunos", e metáforas como "cascata" e "caleidoscópio", e se procure consolidar intenções realísticas mediante uma objetiva política educacional voltada para a inclusão social. 
$\mathrm{Na}$ estruturação de serviços educacionais escolares que possam satisfazer as necessidades básicas de aprendizagem dos alunos, em variadas situações, é preciso que o sistema de ensino conte, também, com a educação especial enquanto a educação comum não seja cabalmente transformada em educação inclusiva. Isto para, de fato, voltar-se para o atendimento da diversidade dos educandos.

\section{EDUCAÇÃO ESPECIAL: PARA QUE E PARA QUEM}

O sentido da educação especial tem sido, muitas vezes, distorcido de modo que ela seja situada como mero mecanismo de discriminação das camadas populares sob a rotulação de problemas de aprendizagem e conseqüente segregação do meio escolar regular. Em razão disso, entendemos ser oportuno resgatar o seu significado:

"Educação Especial é um conjunto de recursos e serviços educacionais especiais organizados para apoiar, suplementar e, em alguns casos, substituir os serviços educacionais comuns, para garantir a educação formal dos educandos que apresentam necessidades educacionais muito diferentes das da maioria das crianças e jovens" (Mazzotta, 1989, p.39).

Para melhor compreensão dos termos dessa definição, particularmente para aqueles que têm se mantido no plano das discussões teóricas sobre essa área, cabe uma breve exposição sobre sua significação no sistema escolar.

"O apoio e a suplementação são auxílios educacionais especiais proporcionados no contexto da escola comum ou regular aos alunos com necessidades educacionais especiais, na classe comum.

APOIO: ocorre quando um professor especializado orienta a equipe da escola e o professor da classe comum, além de prestar atendimento ao aluno auxiliando-o em suas necessidades educacionais especiais para seu melhor acompanhamento do currículo escolar comum e da programação de sua classe. No atendimento ao aluno, atua tendo como referência os conteúdos curriculares e/ou a preparação de materiais didáticos fazendo uso de métodos e recursos especiais. Tal professor será um professor de recursos, podendo ser um consultor, um professor itinerante ou um professor de sala de recursos.

SUPLEMENTAÇÃO: ocorre quando um professor especializado orienta a equipe da escola, os professores das classes comuns e 
presta atendimento ao aluno mediante desenvolvimento de atividades e conteúdos curriculares específicos, além daqueles destinados a todos os alunos de sua classe, de modo a favorecer seu desenvolvimento e aprendizagem e garantir sua escolarização no contexto do ensino regular. São exemplos de conteúdos e atividades específicos o braile, técnicas de comunicação, atividades da vida diária. Para prestar tal auxílio especial, o professor especializado poderá ser itinerante, de sala de recursos ou de classe especial.

SUBSTITUIÇÃO: caracteriza-se como um serviço educacional especial que se torna necessário quando a organização, o currículo, os métodos e os recursos da escola comum e da classe comum não são suficientes ou apropriados para o atendimento das necessidades educacionais dos alunos. Constituem serviços educacionais especiais para substituir a educação comum: a classe especial com organização curricular específica em que o aluno a freqüente com exclusividade, ou seja, em todo o período em que está na escola comum; a escola especial, com organização administrativa e didática específica para determinados grupos de alunos com necessidades educacionais especiais, além de outros menos usuais" (Mazzotta, 1997, pp.15-6).

Se desmistificada do papel de vilã das camadas menos favorecidas da população escolar, ela poderá, pois, ser interpretada no conjunto das alternativas educacionais escolares, que tanto podem ser qualificadas quanto desqualificadas em algum ou nos diversos níveis da administração educacional e organização escolar.

\section{REDEFINIÇÃO DO PAPEL DO ESTADO: TEN- DÊNCIAS DAS POLITICAS EDUCACIONAIS}

Das considerações até aqui expostas podem-se depreender princípios que devem nortear políticas educacionais em direção à constituição da escola enquanto espaço público, para que se viabilize o direito à educação para todos.

A decorrência do sentido de educação especial aqui explorado é que o princípio da inclusão ou não-segregação deve ser o norteador da organização da educação escolar. No entanto, até mesmo para sua concretização, podem se fazer necessários, para alguns alunos, recursos ou serviços especiais. A sua não disponibilização pode se constituir, no limite, em uma ação muito mais discriminatória do que a sua garantia. Ainda, para que se concretize a escola enquanto espaço público é condição que as 
políticas em curso apóiem e estimulem relações de cooperação intra e interescolas, visando a inclusão.

Todavia, em um momento em que se assiste à reforma do Estado assentada em um pressuposto ideológico de que o mercado é o agente principal de promoção de bem-estar social, tem-se, como uma das conseqüências, a restrição da noção de direitos sociais e a ênfase na noção de serviços sociais, sendo necessário examinar o movimento de redefinição do papel do Estado, do Estado de bem-estar social para o Estado mínimo, para uma compreensão das iniciativas localizadas no âmbito educacional.

Em meados dos anos 70, com a perda de dinamismo econômico das principais economias ocidentais, é posto em questão o padrão dominante de relação Estado/sociedade vigente no capitalismo ocidental, desde o fim da Segunda Guerra Mundial. Abala-se o consenso a respeito da intervenção estatal no mercado, visando contornar as crises econômicas e os seus resultados socialmente adversos, bem como seu nível de responsabilização na implementação de politicas sociais.

As análises, presentes na literatura acerca da natureza da crise do Estado social, apontam, com diferentes ênfases, para argumentos tais como: ${ }^{2}$

- o agravamento, nos anos 80, da crise econômica mundial, ao mesmo tempo que gerou aumento $\mathrm{da}$ demanda por programas sociais, resultou em diminuição das receitas públicas;

- a crise fiscal do Estado, que se expressa no crescimento dos gastos públicos sem recursos para seu financiamento;

- a globalização, articulando as ações dos grandes grupos econômicos, resultou no aumento do poder desses grandes grupos e no conseqüente enfraquecimento dos Estados nacionais no delineamento de políticas macroeconômicas;

- centralização e burocratização excessivas da máquina estatal, gerando a ineficiência em seu funcionamento.

- Diante desse quadro de crise do Estado, com menos recursos e menos poder, emergem perspectivas para seu enfrentamento. São formuladas proposições voltadas ao redirecionamento do papel do Estado, abrangendo desde sua relação com a economia até a gestão das políticas sociais. Ainda neste contexto, são delineados modelos direcionados à busca de eficiência do setor público, abarcando iniciativas visando mudanças na lógica de gestão da máquina estatal.

A transformação do papel do Estado e de seu funcionamento interno se puseram como horizonte não só nos países de capitalismo avançado, mas também naqueles em desenvolvimento, com impactos diferentes, é claro, tendo sido referências as iniciativas dos governos Thatcher e Reagan, respectivamente na Grã-Bretanha e nos Estados Unidos.

No Brasil, apesar da tendência à ampliação e à universalização de algumas políticas setoriais, não se concretizou o Estado de bem-estar social. Como diz Weffort:

"Se se entende por welfare State, ou Estado de bem-estar social, o 
conjunto de direitos e dos beneficios sociais que o Estado democrático assegura aos cidadãos nas sociedades modernas, creio que não apenas o Brasil não o superou como está longe de atingi-lo. Welfare State é isso: educação, saúde, previdência, transporte público, seguro-desemprego, garantia de alimentação etc. de boa qualidade e para todos. No caso do Brasil - onde deveríamos incluir também o acesso à terra, o que implica uma reforma agrária -, o que temos é um arremedo disso tudo" (Weffort, 1989, p.3).

Assim como o Brasil, outros países "em desenvolvimento" nem sequer tiveram como realidade o Estado de bem-estar social. No entanto, também a esses se irradiaram as teses neoliberais de defesa do Estado mínimo, que se pautam pela perspectiva de "um Estado mais enxuto e mais eficiente, que prestará um serviço de melhor qualidade aos cidadãos" (Bresser Pereira, 1998, p.341).

A referência a esse movimento de redefinição do papel do Estado que se realiza em âmbito mundial é importante não para aceitá-lo como algo inexorável, mas para possibilitar a explicitação de princípios que têm norteado a implementação das políticas educacionais no Brasil, pelo governo federal e por governos estaduais e municipais.

Levando em conta os limites deste ensaio, vamos nos deter em considerações relativas a um novo modelo de gestão assumido pelo Estado, que transpõe a lógica da gestão privada para a educação pública com seus reflexos nos processos de trabalho da educação básica, em que as iniciativas de avaliação educacional têm centralidade, constituindo o elemento capaz de induzir a competitividade e, em conseqüência, a qualidade, tal como no mercado. Conforme diz Guareschi, o "pressuposto do liberalismo, ou neoliberalismo, hegemônico em nossos dias, tanto no plano econômico, como no filosófico e social, é que o progresso e o desenvolvimento só são possíveis através da competitividade. É o confronto, o choque entre interesses diferentes ou contrários, que vai fazer com que as pessoas lutem, trabalhem, se esforcem para conseguir melhorar seu bem-estar, sua qualidade de vida, sua ascensão econômica” (1999, p.146).

Tal pressuposto, transportado para o campo educacional, possibilita-nos compreender (não necessariamente aceitar) o papel nuclear que vem sendo atribuído, pelo poder público, à avaliação, sendo esta entendida como instrumento capaz de informar sobre a eficiência e produtividade dos serviços educacionais, ou seja, indaga-se sobre os produtos educacionais e as condições e custos de sua produção, ficando sem lugar as questões relativas às finalidades e. aos beneficiários dessa produção.

A avaliação tem sido assumida, nos planos e propostas governamentais, como um mecanismo capaz de promover a melhoria da qualidade $e$ conduzida sob o compromisso de se dar visibilidade e controle público aos produtos ou resultados educacionais, estimulando-se a competição, ao disponibilizar aos usuários elementos para escolha dos serviços ou pressão sobre as instituições ofertantes. Entre as implicações da adoção de um 
ethos competitivo na prestação dos serviços públicos, Abrucio comenta que "o modelo de competição pode levar ao que a ciência política denomina jogo de soma zero. Isto é, o equipamento social vencedor (aprovado pela população) no começo do jogo 'leva tudo' (takes all), ganhando todos os incentivos para continuar sendo o melhor. Já a unidade de serviço público que obtiver as piores 'notas' dos consumidores 'perde tudo', o que resultará indiretamente na aplicação de incentivos para que esse equipamento social continue sendo o pior. Nesse jogo, no entanto, o maior perdedor é o princípio da eqüidade na prestação dos serviços públicos (Pollitt, 1990, p.125), conferindo a alguns consumidores a possibilidade de ser mais cidadão do que outros" (1999, p.189).

Nos moldes em que vem sendo conduzida, a avaliação tem potencial para concretizar a transformaçāo do papel do Estado na gestão da educação pública, Estado que tem assumido como funções prioritárias legislar e avaliar, como expressão de um movimento mais amplo de concretização de um Estado mais enxuto e mais eficiente, que prestará um serviço de melhor qualidade, para alguns cidadãos.

Comentando esse movimento, Afonso explora a expressão "Estado avaliador", que começa a ser utilizada a partir da década de 80 , sobretudo por governos neoconservadores $e$ neoliberais de países centrais. Diz o autor que "para diferentes países, esta expressão quer significar, em sentido amplo, que o Estado adotou um ethos competitivo, decalcado no que tem vindo a ser designado por neodarwinismo social, passando a admitir a lógica do mercado com a importação para o domínio público de modelos de gestão privada cuja ênfase é posta nos resultados ou produtos dos sistemas educativos. Como assinala G. Walford (1990), esta ideologia da privatização, ao enaltecer o capitalismo de livre mercado, conduziu a alterações e mudanças fundamentais no papel do Estado, tanto no nível local, como no nível nacional. Neste sentido, por exemplo, diminuir as despesas públicas exigiu não só a adopção de uma cultura gestionária (ou gerencialista) no sector público, como também induziu a criação de mecanismos de controle e responsabilização mais sofisticados. A avaliação aparece assim como um pré-requisito para que seja possível a implementação desses mecanismos" (Afonso, 1998, p.113).

No Brasil, até o momento, no âmbito da educação básica, não se tem tido a prática de associar aos resultados da avaliação a premiação ou punição. Têm-se divulgado classificaçōes de unidades federadas ou de escolas, elaboradas a partir de resultados obtidos por alunos em testes de rendimento escolar, as quais, no entanto, ao que se sabe, não se vêm traduzindo explicitamente em prêmio ou castigo.

Entretanto, se se considerar que essa é uma prática vigente em países nos quais os governantes brasileiros têm se inspirado para delineamento dos sistema de avaliação, como é o caso da Inglaterra, bem como as decorrências da avaliação dos programas de pós-graduação já vigentes em 
nosso país, será preciso maior atenção a essas iniciativas.

Políticas educacionais formuladas e implementadas sob os auspícios da classificação e seleção incorporam, conseqüentemente, a exclusão, como inerente aos seus resultados, o que é incompatível com o direito de todos à educação.

A própria luta popular para fazer valer esse direito tende a se fragilizar, prevalecendo a busca por conquistas individuais. É ilustrativo desse movimento o comentário feito por Whitty (1998) sobre as reações à reforma educacional na Inglaterra e no País de Gales: “....as escolas, professores e pais enfrentam-se como concorrentes no mercado, e resta-lhes pouco espaço em que possam explorar interesses comuns e empreender ações coletivas".

Nesse quadro é que se situa nosso alerta sobre o paradoxo a que se assiste hoje no âmbito da educação especial:

- de um lado, o estímulo e fortalecimento de iniciativas de atendimento escolar de alunos deficientes nas classes comuns de ensino, sem que sejam acompanhadas de investimentos nos sistemas de ensino que dêem suporte a tal encaminhamento, ou, pior ainda, em alguns casos temse a desativação de serviços e auxílios de educação especial em nome da inclusão;

- de outro, a utilização, cada vez mais intensa, nos sistemas escolares, da avaliação, pautada por um modelo gerador de competição.

A questão que se apresenta é: em nome da inclusão, será que não se está, na realidade, inviabilizando a concretização do direito à educação escolar para parcela de alunos deficientes físicos, sensoriais ou mentais?

É oportuno mencionar algumas conclusões de estudos que, embora tenham sido desenvolvidos em realidades que não a brasileira, trazem uma denúncia que não se pode ignorar, ou seja, do potencial de exclusão inerente às práticas de avaliação de sistema, tal como vêm sendo delineadas no Brasil. Estes estudos foram mencionados por Whitty (1998), ao alertar sobre o potencial das iniciativas de avaliação de provocarem a seleção, pelas escolas, dos alunos que tenham maior probabilidade de serem bem-sucedidos nos testes, observando que entre a clientela menos desejada pelas escolas encontram-se as crianças com necessidades educacionais especiais.

Uma pesquisa citada é a de Gerwitz et al. (1995), que mostraram que as escolas buscam alunos que sejam "capazes", "talentosos", "motivados e comprometidos" e "de classe média"; garotas e crianças de origem e formação sul-asiática são considerados patrimônio especial, em vista do seu potencial de elevar a curva das notas de provas. A clientela menos desejada abrange os que são "menos capazes", apresentam necessidades educacionais especificas, especialmente dificuldades emocionais e comportamentais (Whitty, 1998, p.200).

Comentando os indícios de discriminação contra crianças com necessidades educacionais especiais, o autor menciona que "o prêmio atual pago por crianças portadoras de necessidades especiais pode não ser suficiente, se fizer cair a procura pela 
escola por parte de clientes que, embora representem menos receita, trazem consigo outros atributos desejáveis. Bowe et al. (1992) e Vincent et al. (1995) dão exemplos de escolas que fazem exatamente este tipo de cálculo" (Whitty, 1998, p.201).

$\mathrm{Na}$ mesma direção, Afonso, ao explorar possíveis conseqüências da avaliação de sistemas educacionais, tendo como meio a utilização de testes estandardizados para medir e comparar o rendimento acadêmico dos alunos de diferentes tipos de escolas, destaca que "as boas escolas estão desencorajadas de abrir as suas portas aos estudantes com necessidades educativas específicas...” (1998, p.124).

Essas referências permitem indagar sobre que respaldo encontra nas políticas educacionais em curso a proposta da educação inclusiva, quando essa adota a lógica do mercado, da competição e conseqüentemente da exclusão.

Nossa expectativa é no sentido de que a educação inclusiva concretize-se numa escola para todos não só nos debates políticos, acadêmicos, profissionais, mas contando com uma clarificação de diretrizes e provisão de meios para a ação educacional escolar abrangente, integradora, inclusiva, em todos os níveis da administração educacional e particularmente na escola.

\section{REFERÊNCIAS BIBLIOGRÁFICAS}

Abrucio, F. L. (1999). Os avanços e os dilemas do modelo pós-burocrítico: a reforma da administração pública à luz da experiência internacional recente. In Bresser Pereira, L. C. \& P. S. (orgs.). Reforma do Estado e administração pública gerencial. Rio de Janeiro, RJ: Fundação Getúlio Vargas.

Afonso, A. J. (1998). Politicas educativas e avaliação educacional: para uma analise sociológica da reforma educativa em Portugal (1985-1995). Braga, Universidade do Minho.

Arendt, H. (1997). A condiçióo humatna (R. Raposo, trad.). Posfácio de C. Lafer. Rio de Janeiro, RJ: Forense, $8^{ \pm}$ed.

Brasil, Ministério da Educação (1985). Dia nacional de debate sobre educaçāo: síntese e perspectivas. São Paulo, SP: Cenafor.

(1993). Plano Decenal de Educação para Todos - 1993-2003. Brasilia, DF.

Brasil (1997). Conferência Mundial sobre Necessidades Educativas Especiais: Acesso

e Qualidade. In Declaração de Salamanca e linhas de ação sobre necessidades educativas especiais. Brasília, DF: Corde, $2^{2}$ ed.

Bresser Pereira, L. C. (1998). Reforma do Estado para a cidadania: a reforma gerencial brilsileira na perspectiva internacional. São Paulo, SP: 34; Brasília, DF: Enap.

Draibe, S. \& Wilnês, H. (1988). Welfare State, crise e gestão da crise: um balanço da literatura internacional. Revista Brasileira de Ciências Sociais, (6), 53-78. 
Freitag, B. \& Rouanet, S. P. (1993). Habermas. São Paulo, SP: Ática, $3^{\star}$ ed.

Guareschi, P. (1999). Pressupostos psicossociais da exclusão: competitividade e culpabilização. In Sawaia, B. (org.). As artimanhas da exclusão. Petrópolis, RJ: Vozes, pp.141-56.

Mazzotta, M. J. S. (1989). Evolução da educação especial e as tendências da formacão de professores de excepcionais no Estado de São Paulo. Tese de Doutorado. Faculdade de Educação, Universidade de São Paulo, São Paulo, SP.

(1997). Educação especial: significação dos termos. In Brasil, Ministério da Educação/Secretaria de Educação Especial. Desafios para a educação especial frente a Lei de Diretrizes e Bases da Educação Nacional. Brasilia, DF: SEESP. (2000). Educação inclusiva - escola para todos. Conferência proferida no $\mathrm{V}$ Seminário Nacional do Instituto $\mathrm{Na-}$ cional de Educação de Surdos, em 21/ 9/2000, Rio de Janeiro, RJ.

Sawaia, B. (1999). Exclusão ou inclusão perversa? In Sawaia, B. (org.). As artimanhas da exclusio. Petrópolis, RJ: Vozes, pp.7-13.

Sousa, S. M. Z. L. (1997). Avaliação do rendimento escolar como instrumento de gestão educacional. In Oliveira, D A. (org.). Gestão democrática da educação. Petrópolis, RJ: Vozes, pp.264-83.

(1999). Educação inclusiva: realidade e utopia. Lide/Instituto de Psicologia, Universidade de São Paulo. São Paulo, SP (mimeo)

(2000). Avaliação e políticas educacionais: iniciativas em curso no Brasil. In Silva, I. F. \& Hidalgo, A. M. (orgs.). Educação e Estado: as mudanças nos sistemas de ensino do Brasil e do Paraná, na década de 90. Londrina, PR UEL (no prelo).

Sousa, S. M. Z. L. \& Prieto, R. G. (1999). Politica de atendimento aos portadores de necessidades educacionais especiais da rede municipal de ensino de São
Paulo; ações direcionadas ao portador de deficiencia mental. Relatório de pesquisa. Faculdade de Educação, Universidade de São Paulo. São Paulo, SP

Unicef (1989). Declarafĩo Mundial sobre Educação para Todos e Plano de açāo para satisfazer as necessidades básicas de aprendizagem. Tailândia.

Weffort, F. C. (1989). Não ao apartheid social. Folha de S. Paulo, 14 de outubro, p.A2.

Whitty, G. (1998). Controle do currículo e quase-mercados: a recente reforma educacional na Inglaterra e no País de Gales. In Warde, M. J. (org.). Novas politicas educacionais: críticas e perspectivas. São Paulo, SP: Pontifícia Universidade Católica de São Paulo, pp.193-209.

\section{NOTAS}

1 A esse respeito, consultar Mazzotta, M. J. S. Do direito do portador de deficiencia à educação. Anais do $X V$ Congresso da Federação das APAEs. São Paulo, SP: $30 / 6$ a 3/7/1991, pp.49-52; Mazzotta, M. J. S. Educação especial no Brasil. História e políticas públicas. São Paulo, SP: Cortez, 1996.

2 Em artigo de $S$. Draibe e W. Henrique (1988) é apresentada uma sistematização de interpretações, oriundas de diferentes vertentes teóricas, referentes à crise do welfare State, as quais são parcialmente mencionadas neste texto.

Recebido em novembro/2000. 